\title{
A STUDY ON MANUFACTURING PROCESS OF CUSTOMISED DOORS AT G9 COMPANY IN MYSURU CITY
}

\author{
SINDHU. N \& AASHISH. C. I \\ Department of Management and Commerce, Amrita School of Arts and Sciences,
}

Amrita Vishwa Vidyapeetham, Mysuru, India

\begin{abstract}
In this study an attempt was made to know the different manufacturing process that is conducted in one of the reputative manufacturing company of doorways, interiors, wood way that is located in Mysore city called G9.

This company in well known for its best quality the cost better customer satisfaction and the year the consumption of profit. This company includes good labour intensive and good working environment this company will take the responsibility they mainly aims at better quality conscious.

KEYWORDS: Production, Manufacturing Process, Strategy, Quality, Companies \& Developing \& Environment
\end{abstract}

Received: Dec 02, 2018; Accepted: Dec 22, 2018; Published: Feb 05, 2019; Paper Id.: IJMPERDFEB201959

\section{INTRODUCTION}

Manufacturing is the production of raw material into finished goods on a large-scale machine utensil or instruments synthetic and organic processing or system.

In the G9 is a one of the reputed manufacturing company in Mysore of doorways, interiors, wood way. The finished goods may be sold to other manufacturing or a production of other goods or complex product, such as aircraft, household appliance, furniture, automobile from the whole seller to end user consumer, manufacturing processes starts with a product design and material specification from which the product is prepared.

\section{OBJECTIVES}

- $\quad$ To find the correlation between quality of the door as a component and sales of door's.

- To evaluate the manufacturing process of doorways and wood ways.

- $\quad$ To study the manufacturing process of G9 company in Mysore.

- To understand the different interiors done by G9 company.

\section{METHODOLOGY}

The present study is conducted with the combination of primary as well as secondary data.

A questionnaire was distributed among the respondents to collect the data. A thorough analysis was made to get reasonable inputs, which learnt from the support and existing literatures. 40 samples of Interiors Decorated Limited(manufacturing company limited) have been selected from the universe of Mysore city. A structured questionnaire has been formulated with its question for the study. The study has been conducted during March 
2018 to July 2018.

\section{LITERATURE REVIEW}

- According to the recent research published by Mirko Sokovic, Jelena Jovanovich Zdravko Krivokapic Aleksandra in 2009, have the proposition or concept that the steady enhancement utilization of 7 fundamental standard tool, which has an agreement institution proceed from a stable to energetic progress position or level was presented.

- According to the study conducted by Casio, 2006 Cholusuke et.al, 2004, on manufacturing process having effective support exercise be likely a comprehend the importance of their maintenance management initiatives.

- Excessive statement belonging has frequently recognized while penniless management (Burt 2004). JIT has been the representation of a statement authority technique process. It has methodical near which minimize the statement by possess supplies appear at manufacture and issuance extremity unique when needed.

- According to the point of Petts in 1986 and Baneju and Kim 1995 have mentioned that waste can never be a value for a product he also suggested that the best solution for reduction of cost is to element the wastage of a product in the industry.

- Samuel H. Huang, Peng Liu, Abhiram Mokasadar and Liang Hon, thirty years of their development had brought out supplement manufacturing process and supplement of manufacturing builds a part by including materials one layer at the same time, according to comprised $3 \mathrm{~d}$ solid model because of the above thing the author eliminate fixation, cod ants and cutting tools and other resources because of this structure of manufacturing it gives upgrade of output.

- G. Keong Leong, David L Snyder, Peter T word have defined properly in research conventional on manufacturing strategy has no definite acknowledge the contrast between the process and satisfied research.

- G. S. Dangayach, S. G. Deshmukh, have to classify the old procedure in the literature into theoretical, expressive, factual, investigative trial territorial and analytic lengthwise approaches.

Manufacturing process of strategy has entrance significant research attentiveness is made is review the position of literature in the manufacturing process and operation associated issues.

- Alberto De Toni, Stefano Tonehia, in this article, a venture is made to classify the extensive literature respecting manufacturing pliability process the aim is donate to the theoretical array of the debate. Whose overgrowth plays witness an affluence of themes and the difficulty of acquire particular and original and straight forward framework.

- Jawahar J. Rao, Vasanth a camera manufacturing process has all along been immovable to market and substantial changes, hence, the need to conduct if an pliability and sharpness into the entire supply chain in order to ensure the customer accept the right product at the right time and with good quality, however, difficult to be achieved the supreme framework due thought of raw material opportunity under management, immovable manufacturing process systems and association.

- Ahmad Majoli Bin Abdul-Rani mesfin, Gizaew, YeuriYurof, research outline to the quality product reproduction and enlargement of the unprejudiced manufacturing alliance for arithmetical dominance of the machines becomes 
a noteworthy topic.

- Chiva Ramakrishna, Karanam Krishna machining is the important manufacturing process, which involves the operation of detach the stuff from a work segment in the form of a piece. Assemble is the compulsory where compact liberality on the extent and conclude to be in need of being such an important process in the manufacturing industry.

- Green manufacturing has been appearing as a solution approach in the manufacturing industry try to find to be become a territory continual and across the board aggressive, as a developing country, has to balance both operational and environmental performance.

- Joshuayitagesu Yima, Kitaw Daniel, the purposes of this article is to investigate manufacturing companies performance measures and measurement systems in developing countries, the review research followed a systematic reviewing strategy and process, which has been used for performance measurement researches.

\section{ANALYSIS AND INTERPRETATION}

To find the correlation between quality of the door as a component and sales of door's

Table 1: Descriptive Statistics

\begin{tabular}{|l|c|c|c|}
\hline & Mean & Std. Deviation & N \\
\hline Quality & 37.50 & 10.408 & 4 \\
\hline Sales & 25.00 & 19.579 & 4 \\
\hline
\end{tabular}

Table 2: Correlations

\begin{tabular}{|c|l|c|c|}
\hline \multicolumn{2}{|c|}{} & Quality & Sales \\
\hline \multirow{3}{*}{ Quality } & Pearson Correlation & 1 & .613 \\
\cline { 2 - 4 } & Sig. (2-tailed) & & .387 \\
\cline { 2 - 4 } & $\mathrm{N}$ & 4 & 4 \\
\hline \multirow{3}{*}{ Sales } & Pearson Correlation & .613 & 1 \\
\cline { 2 - 4 } & Sig. (2-tailed) & .387 & \\
\cline { 2 - 4 } & $\mathrm{N}$ & 4 & 4 \\
\hline
\end{tabular}

Table 1 represents the optimistic correlation cost quality and sales, so when quality increases the sales will increase and when quality decrease sales will decrease making both dependent on each other. In the above shown table sales is a dependent variable and quality is independent variable because the quality is always defined by the company and therefore standard is that is set for the components will be according to the pre determinant factors.

The G9 Company maintained the quality as shown in the table the Karl Pearson analysis says there is a significant relationship between quality and sales.

According to the survey the quality which is maintained shows the consistency graph with respect to the sales.

Since doorway is a CEM (original equipment manufacturing) for their own outlets, it becomes even more evident to ensure that the quality standards are high.

According to the SPSS calculation the correlation between the two factors is 0.6 and the value lies between 0 and 1 therefore there is a significant relationship between quality and sale for there the company has to adopt certain changes which would become even more evidence and the correlation between the factors becomes more stronger. It can also seen 
that quality certification can ensure a value closer to one

To evaluate the manufacturing process of doorways and wood ways

To study the manufacturing process of G9 company of Mysore

\section{GRAPH 1}

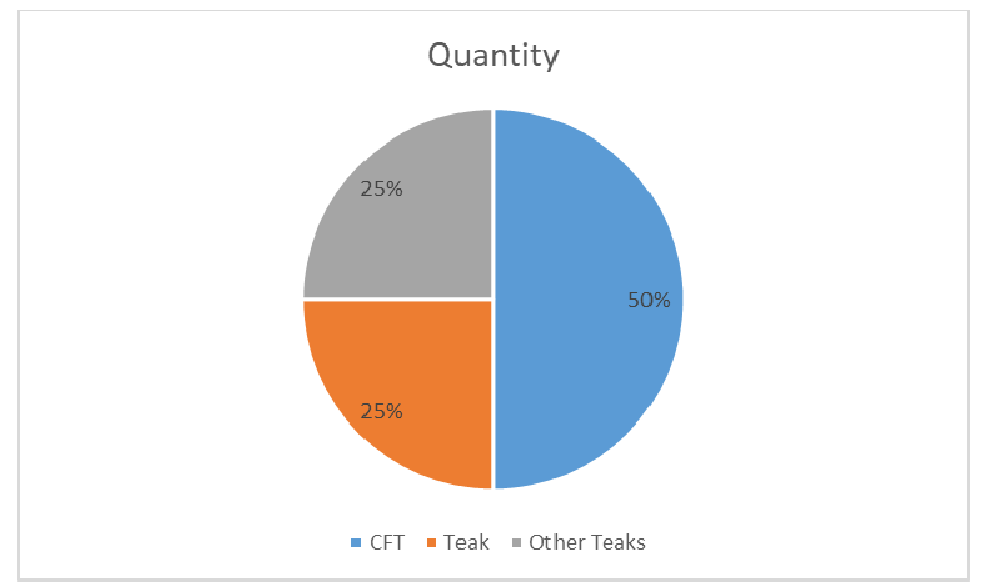

Graph 1 Show that CFT is Purchased in More

Quantity than Teaks and Other Teaks

\section{GRAPH 2}

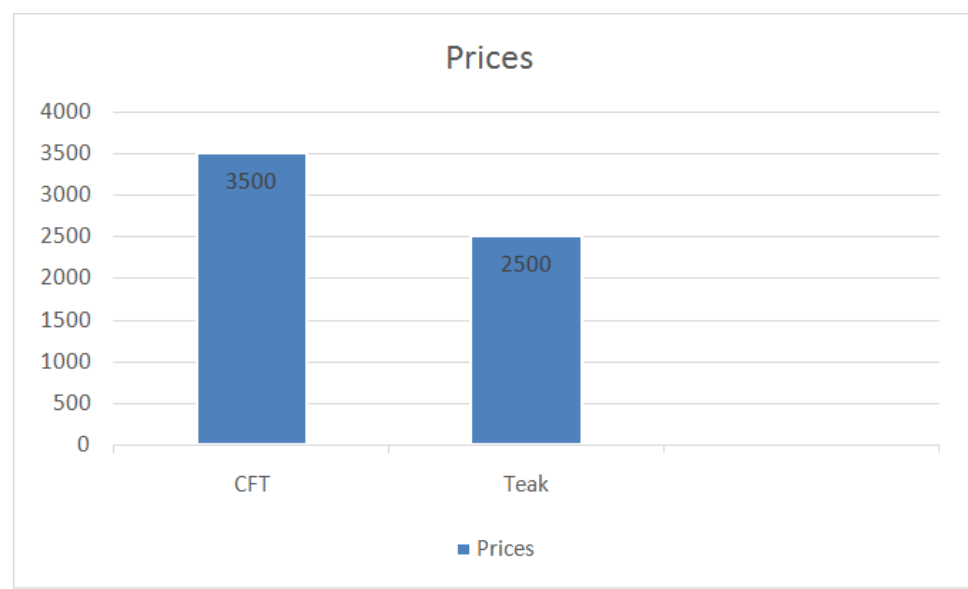

Graph 2 shows the price of various wood types.

To understand the different interiors done by G9 company.

\section{CONCLUSIONS}

These parameters, which are the factors for quality conscious has been standardized and requires certain standard operating procedure to be followed so that it can still be much better than what it is presently by following these procedures a much more customized and quality can be assured so that better opportunities in the future can be ventured and this organization can become a hub for outsourcing of their finished products. Hence, in the final decision from the literature has to study the behaviour of quality under few some key tools in becoming the interesting preferred by the researcher. This company is well known for its best quality in cost, better customer satisfaction and Development of new 
manufacturing processes, having a system of tools designed to minimize manufacturing variation and improves internal yield and reduce external customer defects.

Therefore, it is observed, the researchers are entirely applying pure quality operations within the mixing of the other normal research. The execution and the quality depend upon its manufacturing variations in processes and reducing defects.

\section{REFFERENCES}

1. Mirko Sokovicl, Jelena Jovanovic, Zdravokapic, Alexandra in the basic standard tool in the sustained development business 2009.

2. An effective utilization of solar energy for sustainable development- a future technological development in India Aashish. C.I international journal of mechanical and production engineering research and development (IJMPERD) ISSN (P): 2249-6890; $\operatorname{ISSN}($ E):2249-8001 vil. 7, issue 5, Oct 2017, 399-404

3. A study on working environment and employees performance in J.K Tyres at Mysore Aashish C.I and Kshama P. S. International journal of applied business and economic research ISSN: 0972-7302 available at http: www.serialsjournal.com serials publications pvt. Ltd. Volume15 special issue 2017.

4. Kumar, R. S. Latent Heat Storage Material Evaluation Base on AHP and Topsis for Low Temperature Solar Heating Applications.

5. Dusko Pavletic, Micro Sokovic classification development model by the manufacturing process preparation, 2009.

6. Alexandra Kraemer, song Lli, Daniel Brabandt, Thomas Bohlke, Gisela Lanza et al., standard dominance in the manufacture operation of the SMC insubstantial material 2014.

7. 2006 Cholusuke et al (2004) conducted a study on manufacturing process and it was noted that only 1/3 of the organizations.

8. Taj, M. K., JI, X., Taj, I., \& Hassani, T. M. Different Phase Escherichia Coli Effect on T4 Bacteriophage Lysis and Production.

9. Boute et al, 2004 in the producer of JIT directory and administration, thinking or view Adesh 2003. Lee and Voellan 1993.

10. Samuel H Huang, Peng liu. According to Abhiram Mokasdar. Has Liang Hou. It is allows the plan optimization and the manufacture of the custom built parts on the demand. 
